BMJ Open Sport \& Exercise Medicine

\title{
Does ovulation affect performance in tennis players?
}

\author{
Machiko Otaka, ${ }^{1}$ Shu-Man Chen, ${ }^{2}$ Yong Zhu, ${ }^{3}$ Yung-Shen Tsai, ${ }^{1}$ Ching-Yu Tseng, ${ }^{4}$ \\ Donovan L Fogt, ${ }^{5}$ Boon-Hooi Lim, ${ }^{6}$ Chih-Yang Huang, ${ }^{2,3,7,8}$ Chia-Hua Kuo ${ }^{1}$
}

To cite: Otaka M, Chen S-M, Zhu Y, et al. Does ovulation affect performance in tennis players? BMJ Open Sport \& Exercise Medicine 2018;4:e00305. doi:10.1136/ bmjsem-2017-000305

$\mathrm{C}-\mathrm{YH}$ and $\mathrm{C}-\mathrm{HK}$ contributed equally.

Accepted 20 December 2017

Check for updates

${ }^{1}$ Laboratory of Exercise Biochemistry, University of Taipei, Taipei, Taiwan ${ }^{2}$ Department of Physical Education, Shih Hsin University, Taipei, Taiwan

${ }^{3}$ School of Sports Science, Wenzhou Medical University, Wenzhou, China

${ }^{4}$ Department of Physical Education, Fu Jen Catholic University, New Taipei City, Taiwan

${ }^{5}$ Department of Kinesiology, Health and Nutrition, University of Texas at San Antonio, San Antonio, Texas, USA

${ }^{6}$ Sports Center, University of Malaya, Kuala Lumpur, Malaysia ${ }^{7}$ Department of Healthcare Administration, Asia University, Taichung, Taiwan

${ }^{8}$ Graduate Institute of Physical Therapy and Rehabilitation Science, China Medical University, Taichung, Taiwan

Correspondence to Dr Chia-Hua Kuo; kuochiahua@ gmail.com

\section{ABSTRACT}

Background Scientific data on the performance of collegiate female tennis players during the menstrual phases are scarce.

Trial design Double-blind, counter-balanced, crossover trials were conducted to examine whether tennis performance was affected during menstruation, with and without dehydroepiandrosterone sulfate (DHEA-S) supplementation.

Methods Ten Division 1 collegiate tennis players (aged 18-22 years) were evenly assigned into placebosupplemented and DHEA-supplemented ( $25 \mathrm{mg} /$ day) trials. Treatments were exchanged among the participants after a 28-day washout. Tennis serve performance was assessed on the first day of menstrual bleeding (day 0/28) and on days 7,14 and 21 .

Results Mood state was unaltered during the menstrual cycles in both trials. The lowest tennis serve performance score (speed times accuracy) occurred on day 14 $(P=0.06$ vs day $0 ; P=0.01$ vs day 21$)$ in both placebo and DHEA trials. Decreased performance on day 14 was explained by decreased accuracy ( $P=0.03$ vs day $0 / 28$; $P=0.01$ vs day 21 ), but not velocity itself. Isometric hip strength, but not quadriceps strength, was moderately lower on day 14 ( $\mathrm{P}=0.08$ ). Increasing plasma DHEA-S (by $\sim 65 \%$ ) during the DHEA-supplemented trial had no effects on mood state, sleep quality or tennis serve performance. Conclusion We have shown that menses does not affect serve performance of collegiate tennis players. However, the observed decrement in the accuracy of serve speed near ovulation warrants further investigation.

\section{INTRODUCTION}

Some world-class tennis players have attributed losses to compromised tennis skills during menses. ${ }^{1}$ Among marathon runners, $\sim 30 \%-50 \%$ reported that their menstrual cycle seemed to negatively impact training and performance. ${ }^{2}$ However, athletes from other sports disciplines have reported no perceived change in performance $(62 \%)$ during menses, with $71 \%$ of the athletes feeling better during the first 14 days and feeling worst just before menses itself. ${ }^{3}$ Surprisingly, assessments on sports performance during the entire menstrual cycle among female athletes of various competition levels are currently unavailable.

\section{What are the new findings?}

- Tennis serve performance decreases near ovulation in elite tennis players.

- Menstruation period does not appear to lower tennis serve performance in elite tennis players.

- Increasing dehydroepiandrosterone sulfate level does not improve the serve performance of elite tennis players.

How might it impact on clinical practice in the near future?

Intervention to prevent menstruation bleeding during competition may not be necessary for tennis players.

The days at or around ovulation are generally considered the most accommodating and relaxed of the menstrual cycle for young women. The endurance performance of both trained and untrained women does not seem to be affected during these days. ${ }^{4}$ A study on 10 healthy young women reported an increased fatigability and slower relaxation time during the ovulation period. ${ }^{5}$ Similarly, another well-controlled study on eight regularly menstruating women reported the lowest stretch reflex response of hip muscles around ovulation. ${ }^{6}$ Whether tennis serve performance fluctuates during the menstrual cycle has not been assessed.

Plasma dehydroepiandrosterone sulfate (DHEA-S) level has been found to associate with adaptability against physical training in senior women. ${ }^{7}$ DHEA-S releasing capacity is correlated with adaptation to high-stress conditions of young women. ${ }^{8}$ However, to the best of our knowledge, data from intervention studies during menstrual cycles have not been previously reported to confirm the causal relationship between DHEA-S and sports performance. In this study, we hypothesised that changes of plasma DHEA-S influence tennis serve performance during natural menstrual cycles. 
METHODS

\section{Subjects}

Written inform consent was received from all participants after detailed explanation of the study protocol. Participants were Division 1 collegiate female tennis players in Taiwan. Exclusion criteria were a menstrual cycle outside the range of $28 \pm 1$ day, a history of musculoskeletal or orthopaedic injury, smokers and contraceptive users within the most recent month. A total of 14 female tennis players were initially enrolled in the study, of whom 10 players (aged 18-23 years, body mass $55.8 \pm 1.2 \mathrm{~kg}$, height $162.0 \pm 1.4 \mathrm{~cm}$ ) completed the study. Four participants dropped out due to scheduling conflicts. Training activity was temporarily stopped 1 day before performance assessments.

\section{Experimental protocol}

All assessments (performance-related measures, mood state and DHEA-S) were conducted for two complete menstrual cycles under placebo-supplemented and DHEA-supplemented conditions in a counter-balanced, double-blind, placebo-controlled and crossover manner. A washout time of 28 days separated the two study cycles. For each cycle, assessments started within 24 hours after the onset of menstruating bleeding (day $0 / 28$ ) and were tracked weekly thereafter (days 7, 14 and 21). All participants consumed either DHEA (25 mg daily, Sigma, St Louis, Missouri, USA) or placebo capsule (white starch) provided by the experimenter daily for 4 weeks starting on the first day of menses. Participants received their assigned capsules under the supervision of research staff. On each data collection day, participants reported to the laboratory at 14:00 for measurements of mood state, plasma DHEA-S, subjective fatigue, sleep, muscle strength and serve performance. Plasma samples were collected after lunch at 14:00 to avoid diurnal variation. ${ }^{9}$ Red blood cell count of participants was measured using a haematology analyser (Sysmex, Lincolnshire, Illinois, USA) to monitor anaemia status during the menstruating period.

\section{Profile of Mood State}

A 37-item short form of the Profile of Mood State (POMS) inventory ${ }^{10}$ was used to assess mood state (modified from the original 65 -item questionnaire $\left.{ }^{11}\right)$. The six dimensions (anger, fatigue, depression, tension, confusion and vigour) scores are combined to create a total mood disturbance (TMD) score using the formula: $\mathrm{A}+\mathrm{F}+\mathrm{D}+\mathrm{T}+\mathrm{C}-\mathrm{V}+100$. Lower scores indicate better emotional well-being. All participants completed the POMS inventory in less than $7 \mathrm{~min}$. The POMS TMD score was compared with sleep quality, another strong predictor for depression and mood, ${ }^{12}$ using the Pittsburgh Sleep Quality Index (PSQI) (where higher scores indicate better sleep quality). The correlation coefficient between PSQI and TMD was $-0.59(\mathrm{P}<0.001)$.

\section{Plasma DHEA-S}

Fingertip blood samples were collected into precooled Eppendorf tubes. Blood was centrifuged immediately after plasma collection and stored frozen at $-80^{\circ} \mathrm{C}$ until analysis. DHEA-S concentration was measured on an ELISA spectrophotometer, using commercially available ELISA Kit (Immuno-Biological Laboratories, USA) in accordance with the manufacturer's instruction. ${ }^{13}$

\section{Balance assessment}

A force plate (4060-NC-2000, Bertec, Columbus, Ohio, USA) was used to measure balance ability. Sway ranges of the centre of pressure (COP) in both medial-lateral $(\mathrm{COPx})$ and anterior-posterior direction $(\mathrm{COPz})$ were derived from the force plate data. The sway velocity of the COP $(\mathrm{cm} / \mathrm{s})$ was calculated using total sway distance divided by the standing duration. The sampling frequency was set at $100 \mathrm{~Hz}$. Each participant performed three closed-eye balance tests. Each balance test lasted for $10 \mathrm{~s}$, and the participant was stood on the force plate with their dominant leg. The mean values calculated from the three trials of each balance test were used for data analysis.

\section{Muscle strength}

Muscle strength in the dominant leg was assessed using Biodex isokinetic dynamometer (Biodex, New York, USA). Three maximum isometric contractions were performed using knee extension, hip abduction and hip adduction. Each contraction lasted $5 \mathrm{~s}$ with a $10 \mathrm{~s}$ rest between measurements. Practice/warm-up trials were provided for all participants. Each participant was instructed to perform a maximum effort on each contraction during the testing. The average value of the three trials in each muscle group strength test was normalised by body weight for data analysis.

\section{Tennis serve performance}

Serve performance was determined by both accuracy and velocity (figure 1A). Accuracy was assessed using targets scoring 1 or 3 points. Velocity (mph) of served balls was detected by speed radar device (Bushnell, USA). Before the experiment, a standardised familiarisation of 20 repetitions with $30 \mathrm{~s}$ rest was provided each testing day. After $1 \mathrm{~min}$ of quiet rest, subjects then performed 20 scored repetitions with $30 \mathrm{~s}$ rest intervals. The 20-repetition-score mean 'performance' values were generated using average serve velocity $\times$ averageaccuracy score of each serve. Test-retest reliability of the performance test was $0.71(\mathrm{P}=0.003)$.

\section{Statistical analysis}

The Wilcoxon signed-rank test with repeated measures was used to determine the significant difference of all variables among four measuring time points during a complete menstrual cycle. Mann-Whitney $U$ test was used to determine the mean difference of all measures between the DHEA-supplemented and placebo-supplemented trials. Statistical significance was set at $\mathrm{P}<0.05$ for all analyses. All values are expressed as mean \pm SE. 
A.

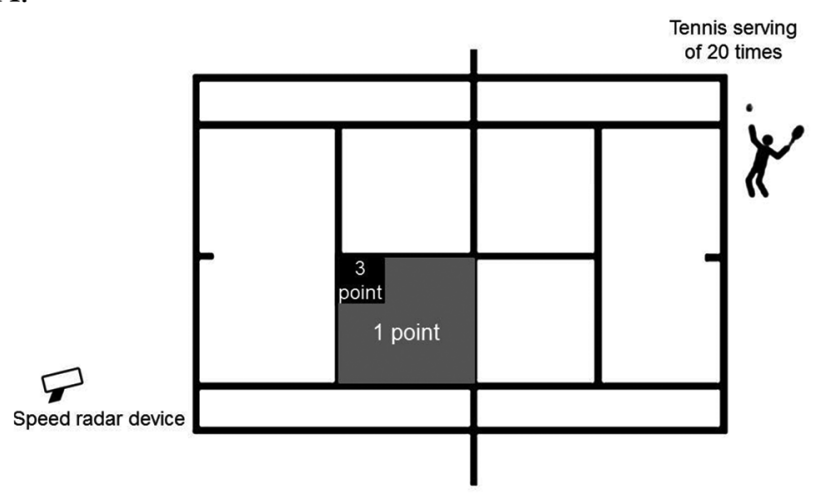

B.

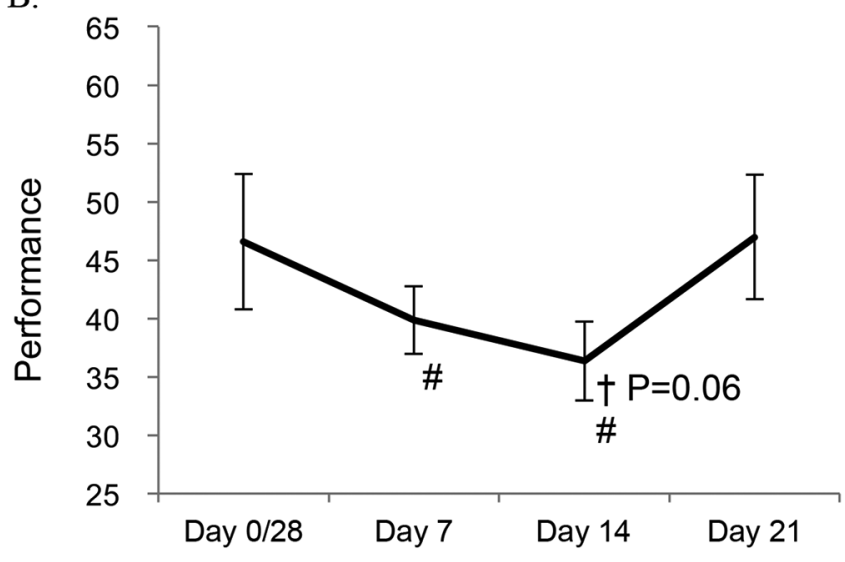

C.

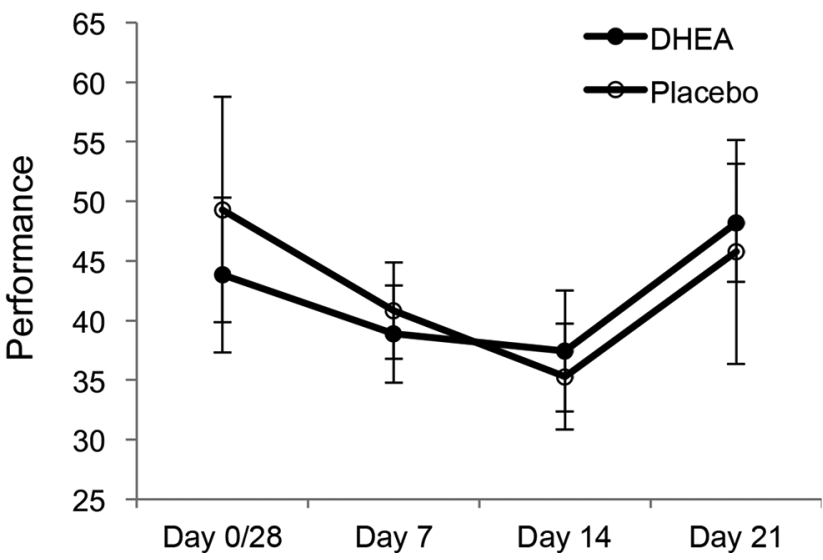

Figure 1 Tennis serve performance fluctuates during menstrual cycles. Serve performance score refers to the mean product of velocity and accuracy from 20 serves. Ball velocity was measured by radar, and accuracy was based on the landing site on the ground in a standard tennis court as illustrated (A). Tennis serve performance decreased on day 14 (main effect of time: $\mathrm{P}=0.01$ vs day 21 and $\mathrm{P}=0.06$ vs day $0 / 28)(B)$. Both dehydroepiandrosterone (DHEA) and placebo trials showed a similar trend (C). †Significant difference against day 0/28; \#significant difference against day 21.

\section{RESULTS}

Oral DHEA supplementation resulted in $\sim 65 \%$ higher plasma DHEA-S levels across the entire menstrual cycle (main effect: $\mathrm{P}<0.05$ ) (table 1). Figure 1 illustrates the scoring method for tennis serve performance. Increased plasma DHEA-S was not associated with performance scores throughout the menstrual cycle. When data of both trials were combined, the lowest performance score occurred on day 14 compared against day 21 (main effect: $\mathrm{P}=0.01$ ) and day $0 / 28$ (main effect: $\mathrm{P}=0.06$ ) (figure $1 \mathrm{~B}$ ). The data from the separate trials showed a similar trend (figure 1C). The performance decrement on day 14 was attributed by decreased accuracy (figure 2A,B) rather than decreased velocity (figure 2C,D).

In the placebo trial, the isometric muscle strength of hip abductors and adductors (figure 3A), but not knee extensors (data not shown), decreased on day $14(\mathrm{P}=0.08$ vs day $0 / 28)$, but this was not statistically significant. No muscle strength changes were observed in the DHEA-supplemented trial. Postural balance ability (closed-eye sway ranges of $\mathrm{COPx}$ ) of tennis players decreased marginally on day 7 (vs day $0 / 28, \mathrm{P}=0.08$ ) and day 14 (vs day $21, \mathrm{P}=0.07$ ) when data from both trials were combined (figure 3B).

A small inverse correlation $(\mathrm{r}=0.31, \mathrm{P}=0.003)$ was found between tennis serve performance and the postural instability measure of balance when all trial and time point data were pooled (figure 4A). The TMD score of POMS and serve performance were not correlated, when both DHEA-supplemented and placebo-supplemented trials were pooled (figure 4B).

\section{DISCUSSION}

The menstrual cycle can cause psychological and physical changes in female athletes, which may in turn affect their sports performance. ${ }^{1-3}$ In the current study, serve performance of elite female tennis players was measured during two complete menstrual cycles. The major finding of the study was that tennis serve performance was significantly lower on day 14, near ovulation, and this was not associated with plasma DHEA-S level. The decreased serve performance was associated with reduced accuracy, but not serve velocity.

No significant difference in knee muscle strength across the entire menstrual cycle was found, which is consistent with previous finding in non-athletes. ${ }^{14}$ Like previous reports, our placebo hip strength data may be related to an increased fatigability and slower relaxation ${ }^{5}$ and the decreased stretch reflex response of hip muscles around ovulation in normally menstruating women. ${ }^{6}$ Taken together, the decreased hip muscle strength with increased postural instability may have contributed, in part, to the decreased tennis serve performance around ovulation. Whether this site-specific change in hip muscle function during ovulation affects task performance to other sport movements or other movements in tennis deserves more investigation.

Mood may affect sports performance for menstruating women, ${ }^{15}$ but the performance and mood data from the current study do not support this theory. Precompetition POMS findings from a study on adolescent basketball players from the UK describe interindividual variation in mood-to-performance relationship among players. ${ }^{16}$ The putative effects of menses could be different for 
Table 1 Plasma dehydroepiandrosterone sulfate (DHEA-S) and red blood cell (RBC) levels during dehydroepiandrosterone (DHEA)-supplemented trial

\begin{tabular}{llllcc}
\hline & Trials & Day 0/28 & Day 7 & Day 14 & Day 21 \\
\hline DHEA-S $(\mu \mathrm{g} / \mathrm{mL})$ & Placebo & $0.9 \pm 0.2$ & $0.9 \pm 0.1$ & $0.8 \pm 0.1$ & $0.9 \pm 0.1$ \\
& DHEA & $1.5 \pm 0.3$ & $1.6 \pm 0.3$ & $1.4 \pm 0.2$ & $1.5 \pm 0.3$ \\
& P & $<0.05$ & $<0.01$ & $<0.01$ & $<0.01$ \\
RBC $\left(\times 10^{6} / \mathrm{mg}\right)$ & Placebo & $3.6 \pm 0.1$ & $3.9 \pm 0.1$ & $3.7 \pm 0.2$ & $3.5 \pm 0.2$ \\
& DHEA & $3.8 \pm 0.1$ & $3.8 \pm 0.2$ & $3.9 \pm 0.1$ & $3.6 \pm 0.1$ \\
& P & $<0.01$ & $\mathrm{NS}$ & $\mathrm{NS}$ & $\mathrm{NS}$ \\
Haemoglobin $(\mathrm{g} / \mathrm{dL})$ & Placebo & $11.0 \pm 0.2$ & $11.6 \pm 0.4$ & $10.5 \pm 0.9$ & $10.3 \pm 0.8$ \\
& DHEA & $11.5 \pm 0.3$ & $11.7 \pm 0.4$ & $11.5 \pm 0.7$ & $11.0 \pm 0.3$ \\
& P & NS & NS & NS & NS \\
\hline
\end{tabular}

performance of specific sport movements, competition outlook and in sports with different numbers of participating team-mates. For example, one's individual movement performance may not be affected, but their mood state could affect their performance within the team. The limited number of athletes and disciplines studied to date limits generalised conclusions on whether mood state is a good predictor of performance among athletes.

Available literature on plasma DHEA-S changes across the menstrual cycle is currently lacking. In this study, we did not observe a noticeable DHEA-S fluctuation during both placebo-supplemented or DHEA-supplemented trials. Furthermore, the causal relationship between plasma DHEA-S and sports performance of elite tennis players was not confirmed in the study. Plasma DHEA-S level is known to correlate significantly with age ${ }^{17}$ mental health, ${ }^{18} 19$ physical fitness ${ }^{13} 20$ and adaptation. ${ }^{7}$ Our lack of findings may be due, in part, to our athletes being members of a highly selective group of a young population endowed with outstanding adaptability and physical fitness. Based on the current findings, coaches and athletes should be advised that supplementing DHEA-S in young tennis players does not provide additional benefit and
A

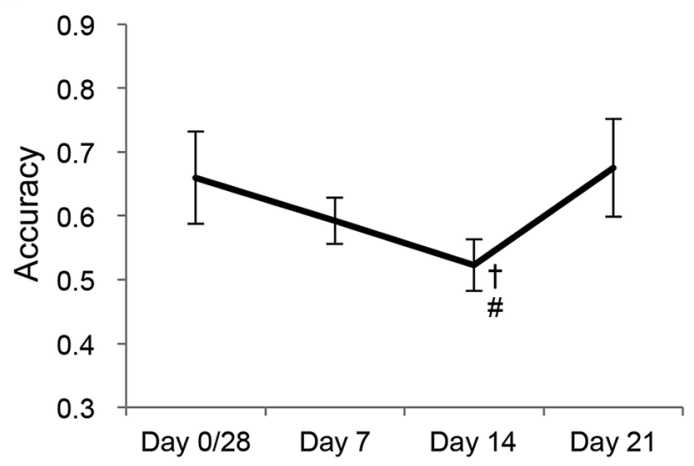

C.

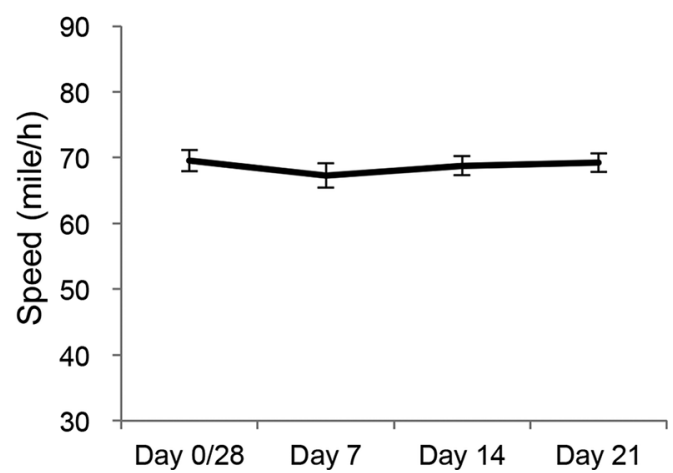

B.

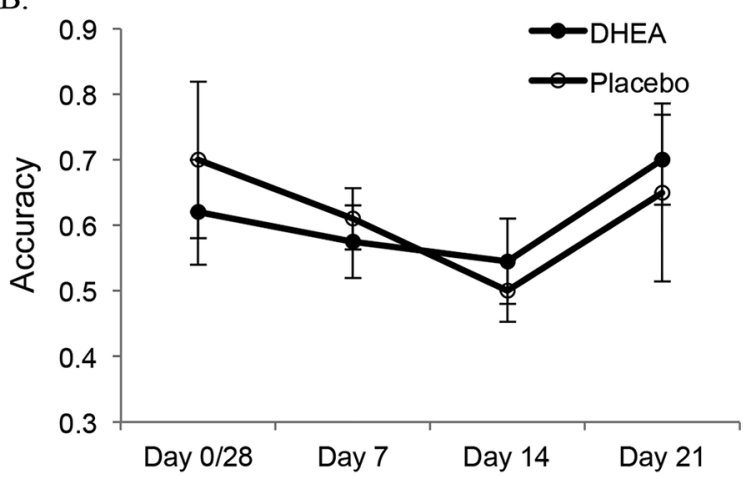

D.

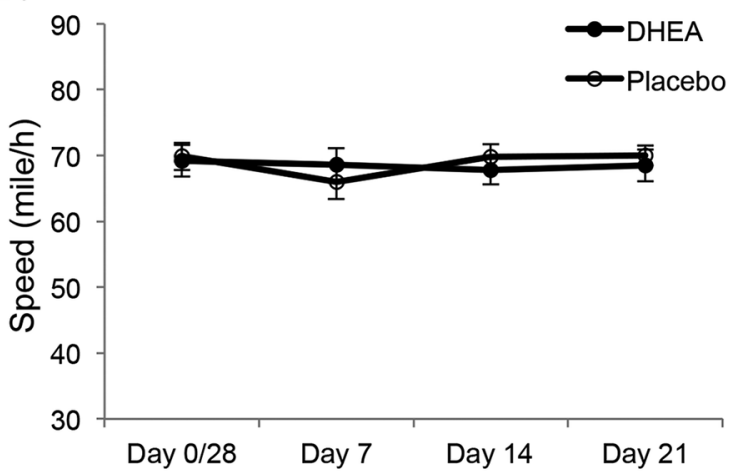

Figure 2 Accuracy and velocity components of tennis serve performance during menstrual cycles. Mean accuracy decreased on day $14(\mathrm{~A})$, and both placebo and dehydroepiandrosterone (DHEA) trials showed similar trend (B). Mean velocity was unaltered during the menstrual cycles (C), and both placebo and DHEA trials showed similar trend (D). †Significant difference against day 0/28; \#significant difference against day 21. 
A.

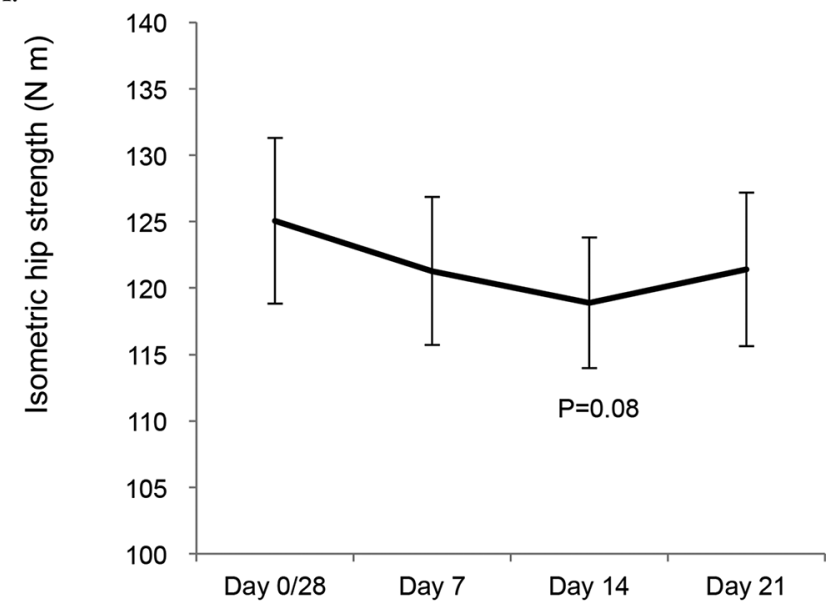

B.

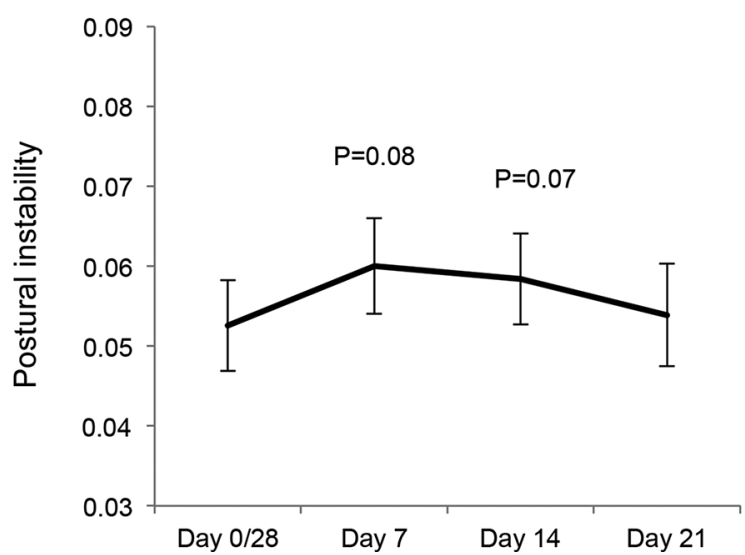

Figure 3 Hip isometric muscle strength and postural instability (sway ranges of the centre of pressure in mediallateral direction) fluctuate moderately during menstrual cycles. The main effect of time on hip strength during abduction (A) was moderately decreased $(P=0.08)$ and postural instability $(B)$ was moderately increased $(P=0.07)$.

appears to be deleterious to their balance ability during the early phase of menstruation.

It has been previously reported that the ovarian contribution of peripheral DHEA-S is highest around ovulation in women. ${ }^{21}$ Since plasma DHEA-S level is determined by a net rate of production and clearance of circulating DHEA-S in the body, the observed result on plasma DHEA-S level suggests that DHEA-S clearance rate from blood may have been increased around ovulation in our subjects. DHEA-S plays an important role in fertility among women, evidenced by an increased spontaneous pregnancy rate under oral DHEA supplementation. ${ }^{22}$ It would be of interest to examine whether DHEA-S demand increases by hip tissues (bone marrow or muscles) during ovulation for pregnancy.

The major limitation of the study is the small number of highly trained Division 1 tennis players in Taiwan. To generalise the knowledge of performance decrement around ovulation from the present data to a broader population of tennis players, various training levels and ages should be evaluated. Another constraint of the study is the use of low-dose DHEA supplementation to
A

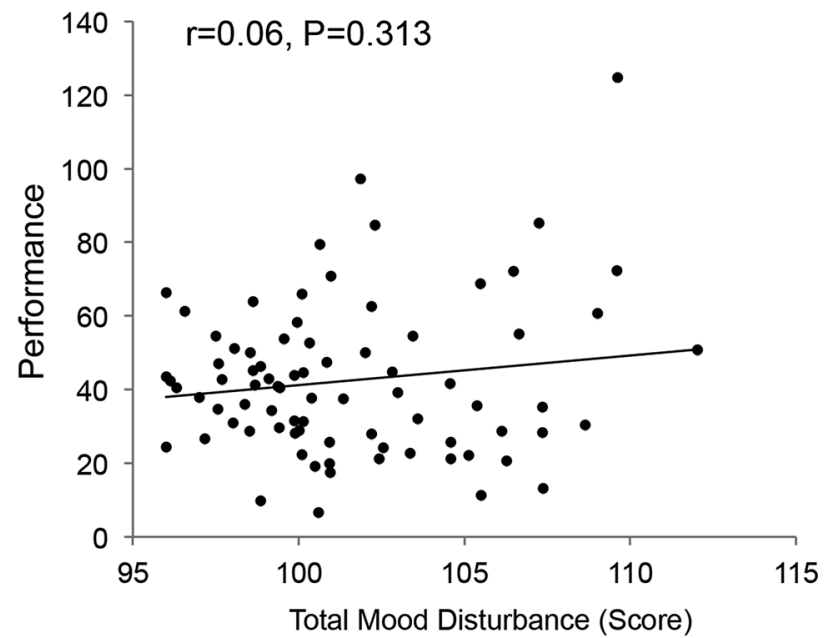

B

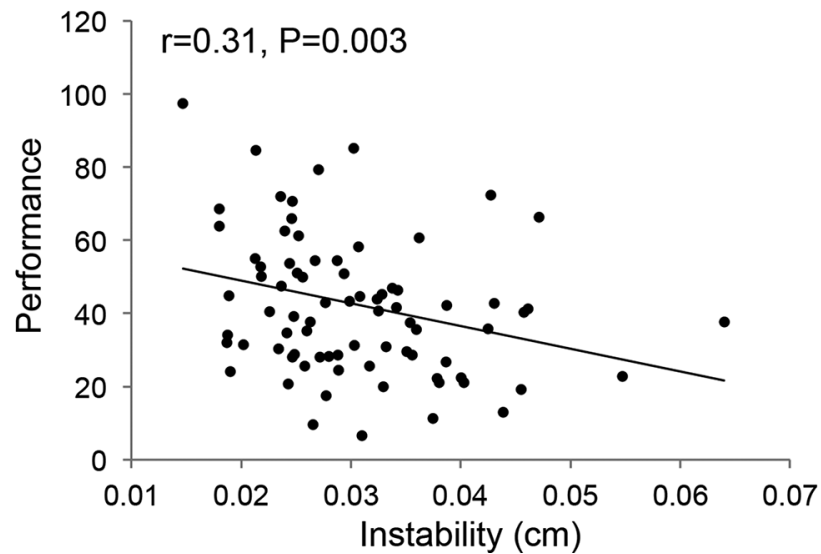

Figure 4 Tennis serve performance moderately correlates with open-eye postural instability among tennis players $(A)$ and not with mood state of female tennis players (B). All time data of elite tennis players were pooled together. Postural instability was measured on a force plate (open-eye sway ranges of the centre of pressure in medial-lateral direction). Mood state was self-reported by total mood disturbance score using the Profile of Mood State.

increase DHEA-S level. The age level of the participants is young and thus DHEA-S deficiency is less likely an issue. Furthermore, tennis serve performance is partly linked with balance ability and hip muscle strength involving postural control at very high intensities. Our findings using this specific sport movement may not be applicable to other aspects of the tennis game or other sports disciplines.

\section{CONCLUSION}

The results of the study demonstrated a poorer tennis serve performance around ovulation in normally menstruating collegiate tennis players, relative to day 0/28 (menstruation) and day 21 (premenstrual period). This performance decrement is mostly explained by decreased accuracy and moderately associated with decreased balance control of posture and hip muscle strength. Increasing DHEA-S level does not affect the 
serve performance of young competitive collegiate tennis players. Our data suggest that ovulation may tax the coping capacity of female athletes when performing the tennis serve. Overall the findings of the study are useful for coaches who train female tennis players. They could also provide useful information for the planning of training and competition. The plausible effects of increased postural instability on serve accuracy warrant further investigation.

Acknowledgements We would like to thank the staff at the University of Taipei for technical assistance.

Funding This study was funded by Chinese Taipei University Sports Federation, Ministry of Science and Technology of the Republic of China (MOST 103-2410-H128-008), University of Taipei.

Competing interests The authors declare that they have no conflict of interest in any aspect.

Patient consent Obtained.

Ethics approval The China Medical University Institution Review Board approved the study protocol (CMUH103-REC3-006 CR-1).

Provenance and peer review Not commissioned; externally peer reviewed.

Data sharing statement Data is available upon request.

Open Access This is an Open Access article distributed in accordance with the Creative Commons Attribution Non Commercial (CC BY-NC 4.0) license, which permits others to distribute, remix, adapt, build upon this work non-commercially, and license their derivative works on different terms, provided the original work is properly cited and the use is non-commercial. See: http://creativecommons.org/ licenses/by-nc/4.0/

(c) Article author(s) (or their employer(s) unless otherwise stated in the text of the article) 2018. All rights reserved. No commercial use is permitted unless otherwise expressly granted.

\section{REFERENCES}

1. R S. The last taboo in sport: I have nightmares about getting my period at Wimbledon: Telepgraph, 2017.

2. Bruinvels G, Burden R, Brown N, et al. The prevalence and impact of heavy menstrual bleeding (menorrhagia) in elite and non-elite athletes. PLoS One 2016;11:e0149881.

3. Kishali NF, Imamoglu O, Katkat $D$, et al. Effects of menstrual cycle on sports performance. Int J Neurosci 2006;116:1549-63.

4. Oosthuyse T, Bosch AN, Jackson S. Cycling time trial performance during different phases of the menstrual cycle. Eur J Appl Physiol 2005:94:268-76.
5. Sarwar R, Niclos BB, Rutherford OM. Changes in muscle strength, relaxation rate and fatiguability during the human menstrual cycle. $J$ Physiol 1996;493(Pt 1):267-72.

6. Casey E, Hameed F, Dhaher YY. The muscle stretch reflex throughout the menstrual cycle. Med Sci Sports Exerc 2014;46:600-9.

7. Huang YJ, Chen MT, Fang CL, et al. A possible link between exercise-training adaptation and dehydroepiandrosterone sulfate- an oldest-old female study. Int J Med Sci 2006;3:141-7.

8. Rasmusson AM, Vasek J, Lipschitz DS, et al. An increased capacity for adrenal DHEA release is associated with decreased avoidance and negative mood symptoms in women with PTSD. Neuropsychopharmacology 2004;29:1546-57.

9. Carandente F, Angeli A, Candiani GB, et al. Rhythms in the ovulatory cycle. 3rd: cortisol and dehydroepiandrosterone sulphate (DHEA-S). Chronobiologia 1990;17:209-17.

10. Wang HT, Chen SM, Lee SD, et al. The role of DHEA-S in the mood adjustment against negative competition outcome in golfers. $J$ Sports Sci 2009;27:291-7.

11. McNair D, Lorr M, Droppleman L. Manual for the profile of mood states. San Diego, CA: Educational and Industrial Testing Service, 1971.

12. Saunders EF, Fernandez-Mendoza J, Kamali M, et al. The effect of poor sleep quality on mood outcome differs between men and women: a longitudinal study of bipolar disorder. J Affect Disord 2015;180:90-6.

13. Lee WC, Chen SM, Wu MC, et al. The role of dehydroepiandrosterone levels on physiologic acclimatization to chronic mountaineering activity. High Alt Med Biol 2006;7:228-36.

14. Fridén $C$, Hirschberg AL, Saartok T. Muscle strength and endurance do not significantly vary across 3 phases of the menstrual cycle in moderately active premenopausal women. Clin J Sport Med 2003;13:238-41.

15. Beedie CJ, Terry PC, Lane AM. The profile of mood states and athletic performance: two meta-analyses. J App/ Sport Psychol 2000;12:49-68.

16. Chappell A. Mood and performance relationships among players at the world student games basketball competition. J Sport Behav 2001;24:182.

17. Orentreich N, Brind JL, Rizer RL, et al. Age changes and sex differences in serum dehydroepiandrosterone sulfate concentrations throughout adulthood. J Clin Endocrinol Metab 1984;59:551-5.

18. Lennartsson AK, Theorell T, Kushnir MM, et al. Perceived stress at work is associated with attenuated DHEA-S response during acute psychosocial stress. Psychoneuroendocrinology 2013;38:1650-7.

19. Lennartsson AK, Theorell T, Kushnir MM, et al. Low Levels of Dehydroepiandrosterone Sulfate in Younger Burnout Patients. PLoS One 2015;10:e0140054.

20. Goldman N, Glei DA. Sex differences in the relationship between DHEAS and health. Exp Gerontol 2007;42:979-87.

21. Abraham GE. Ovarian and adrenal contribution to peripheral androgens during the menstrual cycle. J Clin Endocrinol Metab 1974:39:340-6.

22. Fusi FM, Ferrario M, Bosisio C, et al. DHEA supplementation positively affects spontaneous pregnancies in women with diminished ovarian function. Gynecol Endocrinol 2013;29:940-3. 


\section{Correction: Does ovulation affect performance in tennis players?}

Otaka M, Chen S, Zhu R, et al. Does ovulation affect performance in tennis players? BMJ Open Sport Eै Exercise Medicine 2018;4:e000305. doi: 10.1136/bmjsem-2017000305 corr 1

The authors want to alert readers to the following error identified in the published version.

The third co-author's name was incorrectly spelled as 'Yong Zhu'. The correct name of the co-author is 'Rong Zhu'.

Open access This is an Open Access article distributed in accordance with the Creative Commons Attribution Non Commercial (CC BY-NC 4.0) license, which permits others to distribute, remix, adapt, build upon this work non-commercially, and license their derivative works on different terms, provided the original work is properly cited and the use is non-commercial. See: http://creativecommons.org/licenses/by-nc/4.0

C Author(s) (or their employer(s)) 2018. Re-use permitted under CC BY-NC. No commercial re-use. See rights and permissions. Published by BMJ.

BMJ Open Sport Exerc Med 2018;4:e000305corr1. doi:10.1136/bmjsem-2017-000305corr1

Check for updates 